\title{
O papel profissional do médico-veterinário na atividade de Terapia Assistida por Animais (TAA)
}

\section{The veterinarian's professional role in Animal Assisted Therapy}

\section{Resumo}

A Terapia Assistida por Animais (TAA) é uma das inúmeras interações entre homens e animais. Essa relação consiste na utilização de animais como coterapeutas que auxiliam pacientes a evoluir positivamente em seus quadros físicos, emocionais e sociais. Este estudo procura enfatizar a necessidade e importância do médico-veterinário para o desenvolvimento e sucesso da TAA.

\section{Abstract}

Animal-assisted therapy is one of the innumerable interactions between humans and animals. This relationship consists on using animals as co-therapists that help patients evolve positively their physical, emotional, and social states. This study aims to emphasize the need and importance of veterinarians for the development and success of animal-assisted therapy. 
Natália Canevassi da Silva ${ }^{1}$ Marisol Mara Madrid ${ }^{2}$ Milena Carine da Costa Santos ${ }^{2}$ Flávia de Almeida Lucas ${ }^{3}$ Valéria Nobre Leal de Souza Oliva ${ }^{4}$
Avenida Policial Militar Carlos Aparecido Buzon, 161

Dona Amélia, Araçatuba/SP, CEP: 16050-710

荡 naticanevassi@hotmail.com
Palavras-chave

Terapia. Animais. Veterinária.

\section{Keywords}

Therapy. Animals. Veterinary.

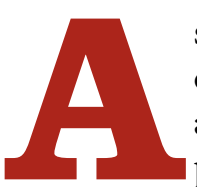

s interações entre homens e animais estão presentes desde os primórdios da civilização. Com o passar dos anos, os animais deixaram de ser utilizados apenas para produção de alimentos e derivados e passaram a ser amplamente adquiridos para companhia, sendo enquadrados, em muitos casos, como membro da família. Atualmente, a interação em maior ascendência é a Terapia Assistida por Animais, conhecida pela sigla TAA. (PEREIRA; PEREIRA; FERREIRA, 2007).

A TAA consiste em uma técnica em que animais de companhia (principalmente cães e cavalos) são utilizados como coterapeutas, atuando com profissionais da saúde em ambientes hospitalares ou asilos, entre outras instituições. A relação dos pacientes com animais é extremamente benéfica nos aspectos emocional, físico e social.

Graduanda em Medicina Veterinária na Faculdade de Medicina Veterinária da Universidade Estadual Paulista (FMVA-Unesp), Araçatuba/SP, Brasil. 
O contato de pacientes com cães desvia o foco da doença, propicia alívio ao sofrimento e estimula a troca mútua de carinho. Por meio de caminhadas com os animais, do ato de escová-los e acariciá-los, os pacientes em tratamento podem ser estimulados a realizar atividades físicas que trazem benefícios à saúde. Além disto, o convívio com cães é capaz de auxiliar na regulação da pressão arterial e aumentar os níveis de serotonina no organismo (DOTTI, 2005).

A TAA também é responsável por melhorar o convívio social de pessoas institucionalizadas e facilitar a abordagem do profissional de saúde ao paciente. Turner (POR QUE..., 2001) observou que, após algumas consultas com animais, pacientes extremamente introvertidos começaram a interagir mais facilmente com psicólogos e psiquiatras.

Abreu et al. (2009) verificou que o contato constante de idosos com animais estimula o uso da memória recente, além de possibilitar uma boa interação com os funcionários que lidam com os internos todos os dias, alterando positivamente as atividades rotineiras.

Volpi e Zadrozny (2012) referiram que a presença do animal desconcentra o paciente de sua dor e traz alívio à tensão e à ansiedade. As pessoas tornam-se mais cooperativas, sociáveis e afáveis. Os animais também estimulam o sistema imunológico, auxiliam no processo de aprendizagem, melhoram a capacidade motora e a qualidade da comunicação entre pacientes e com profissionais e cuidadores.

Para que a TAA apresente bons resultados é necessária a participação de inúmeros profissionais, entre eles o médico-veterinário. Esse profissional é o único capacitado para zelar pela saúde dos animais terapeutas e pode, ainda, observar manifestações comportamentais e garantir o seu rendimento adequado na atividade (ANDERLINE; ANDERLINE, 2007). O médico-veterinário deve acompanhar as sessões de TAA, pois, dessa forma, pode observar alterações comportamentais e físicas dos animais, inclusive indicar a melhor forma de trabalhar com diferentes espécies e raças, garantindo o bem-estar dos animais durante a atividade (FLÔRES, 2009).

Os deveres do médico-veterinário responsável por atividades de TAA têm início no momento da seleção de um animal apto para a função de terapeuta. Muitos animais são selecionados ainda filhotes e devem passar por avaliação física e comportamental. Entre as características que devem ser consideradas no momento de seleção do animal que participará da TAA, Dotti (2005) ressalta: a reação diante de algumas brincadeiras, o grau de irritabilidade do animal, sua resistência e reação quando carregado ou pego no colo e a capacidade de socialização.
Os cães selecionados para participar da TAA devem passar por treinamento com profissionais qualificados, para serem capacitados a obedecer a comandos básicos, ser receptivos a estranhos, permitir o toque e ser adequadamente conduzidos com a guia. As condições físicas do animal em questão também deverão ser consideradas antes do início da atividade.

Quando as atividades de TAA se iniciam, a realização de manejo sanitário adequado é fundamental para garantir a saúde dos animais. O médico-veterinário é responsável por garantir que a medicina preventiva seja realizada adequadamente. É necessário que algumas medidas sejam tomadas, como: vacinação anual com vacina polivalente (V10), vacinação anual contra raiva, vermifugação a cada quatro meses (com reforço), exame parasitológico semestral, controle de ectoparasitas, limpeza dos dentes e orelhas, castração e unhas cortadas e lixadas.

Flôres (2009) destaca que a castração de animais utilizados em TAA não é obrigatória, mas as fêmeas no cio, mesmo que seco, não podem participar de visitas, e o mesmo acontece com cães filhotes e idosos (a idade ideal para o encerramento das atividades de um cão terapeuta é entre oito e nove anos). $\mathrm{O}$ ambiente onde os animais habitam também deve ser mantido adequadamente. É necessário que haja limpeza diária, que remova e descarte dejetos. Além disso, é fundamental que o local possua estrutura que comporte os animais de maneira segura e confortável (Figura 1).

Sendo assim, a presença do profissional veterinário é fundamental, desde a seleção dos animais para o trabalho até o seu acompanhamento durante todo o decorrer das atividades terapêuticas.

\section{Objetivos}

O objetivo do presente trabalho foi descrever a função de um médico-veterinário dentro da equipe multiprofissional de TAA e sua importância na garantia de melhores condições sanitárias e comportamentais de cães utilizados nessa terapia. Além disso, foi analisada a validade do envolvimento de estudantes de graduação em projetos de extensão aplicados à TAA.

\section{Material e Métodos}

A pesquisa foi conduzida no canil do projeto de extensão Cão-Cidadão-Unesp, da Faculdade de Medicina Veterinária de Araçatuba (FMVA), na Universidade Estadual Paulista (Unesp), em Araçatuba/SP. Tal projeto, que existe há 12 anos, oferece TAA de forma gratuita a 
diversas instituições de atendimento a idosos, crianças ou adultos com necessidades especiais. Conta com a participação de alunos, professores e funcionários da própria faculdade, além de voluntários da comunidade local.

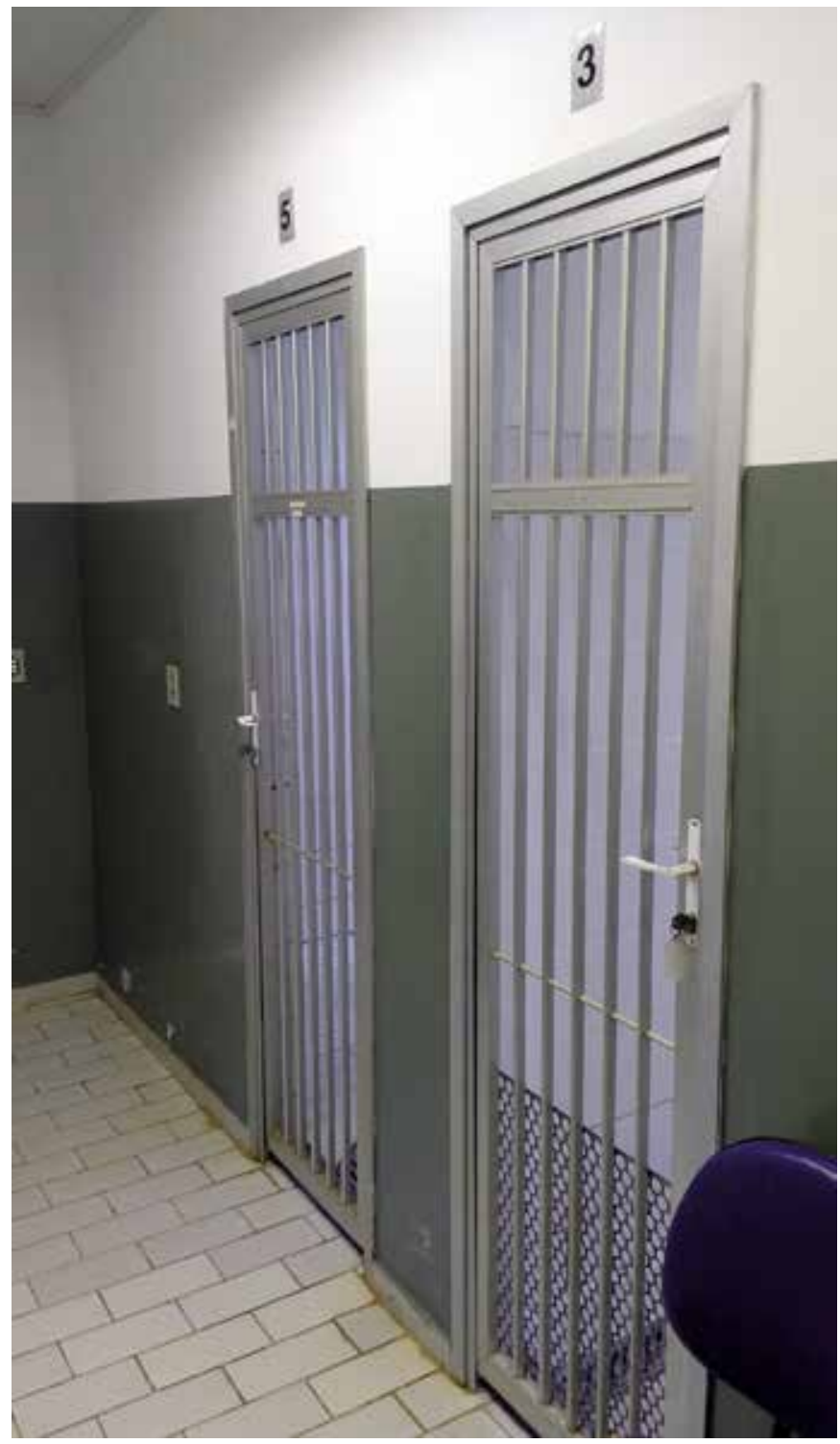

Figura 1 - Cães com acesso a espaço livre e exposição ao sol durante o dia. Fonte: Silva (2017).

O projeto possui atualmente três cadelas preparadas para as atividades de TAA, adultas, da raça labrador retriever, duas castradas e uma não castrada. As cadelas com os nomes Flor de Liz, Boneca e Branca nasceram no próprio canil e são filhas de outros animais terapeutas que atuaram anteriormente no projeto. Habitam o canil em tempo integral e são de propriedade da própria faculdade.

O controle sanitário dos animais é de responsabilidade de dois docentes do curso de Medicina Veterinária que delegam atividades a médicos-veterinários que cursam o programa de residência na área de clínica médica de pequenos animais.

A bolsista do projeto TAA e aluna do terceiro ano do curso de Medicina Veterinária tem como atividade a responsabilidade de controlar o esquema de vacinação, profilaxia de helmintos e de ectoparasitas proposto pelos médicos-veterinários residentes e docentes.

Os animais do projeto TAA são vermifugados a cada quatro meses com vermífugos de amplo espectro e os exames parasitológicos de fezes são efetuados periodicamente para identificação de possíveis parasitoses. Caso algum desses exames seja positivo, é realizada a medicação indicada para o parasito identificado.

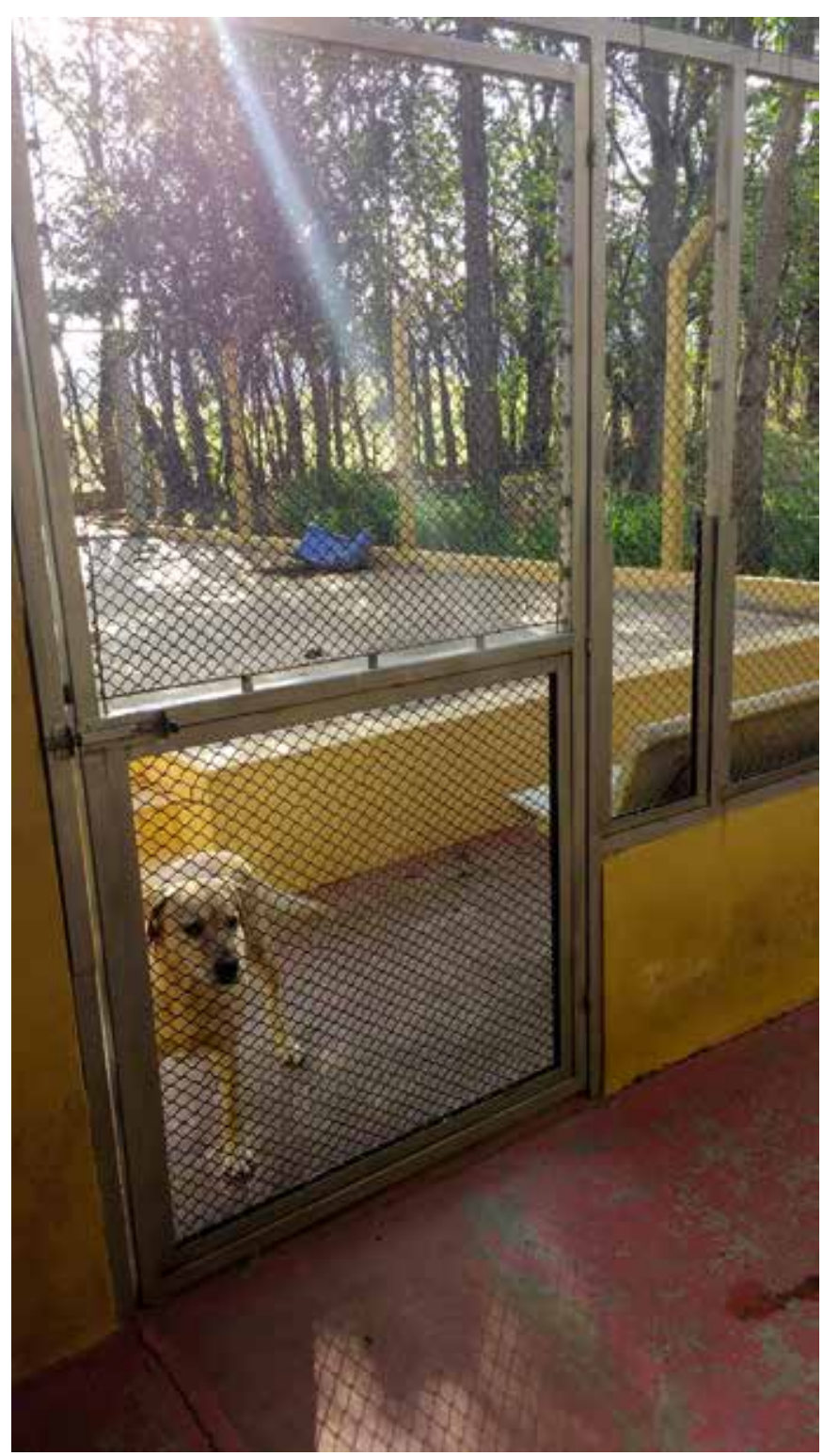

Figura 2 - Baias individuais, onde os animais são recolhidos ao cair da tarde. Fonte: Silva (2017). 
O protocolo de vacinação dos animais terapeutas é representado pela aplicação anual das vacinas contra raiva e a polivalente contra cinomose, parvovirose, coronavirose, adenovirose, parainfluenza, hepatite infecciosa canina e leptospirose, Sorovares Canicola, Grippotyphosa, Pomona e Icterohaemorrhagiae. A vacina contra leishmaniose visceral também é aplicada anualmente, tendo em vista que a doença é endêmica na região de Araçatuba, estado de São Paulo, Brasil.

No protocolo de atividades estabelecidas para prevenção da leishmaniose visceral, os animais são recolhidos ao cair da tarde para as dependências teladas do canil, em baias individuais (Figura 2), onde realiza-se diariamente a aspersão de spray de citronela em todo o dorso dos cães.

Os animais terapeutas são constantemente examinados para manutenção de orelhas e dentes limpos e para se manterem isentos de ectoparasitas. A observação dos animais é tarefa executada por todos que manuseiam os cães, e qualquer alteração identificada é reportada aos médicos-veterinários residentes e aos docentes responsáveis, para as devidas providências.

A alimentação dos animais utilizados para TAA é constituída por ração de boa qualidade (super premium) oferecida duas vezes ao dia (manhã e tarde) sempre nas áreas teladas do canil, em baias individuais.

Em todas as atividades de TAA em que os cães participam há um profissional ou estudante da área de Medicina Veterinária que observa o comportamento dos animais, sendo responsável ainda por controlar o rendimento dos cães e seu bem-estar. Entre as instituições participantes do projeto, o "Lar da Velhice e Assistência Social", localizado em Araçatuba (SP), que abriga cerca de 32 idosos, foi selecionado para o embasamento da pesquisa durante a prática de TAA. Durante um ano e meio foram realizadas visitas semanais, com duração de duas horas. Nessas visitas os cães terapeutas foram levados por alunos da instituição de ensino que participam do projeto como estagiários, voluntários ou bolsistas. Foram observados, então, o rendimento dos cães, o progresso dos pacientes assistidos e o envolvimento e a participação dos membros da equipe.

\section{Resultados e Discussão}

As cadelas que hoje atuam no projeto Cão-Cidadão-Unesp têm demonstrado excelente rendimento nas atividades a que são submetidas e não apresentaram, ao longo do período estudado, nenhuma manifestação comportamental que as desabonasse como animais de terapia. Acredita-se que o sucesso se deva à seleção de animais ao longo dos anos, à escolha de filhotes de outros animais de TAA e às orientações de Dotti (2005) quanto ao temperamento. Além disso, os animais foram adestrados por profissionais da área e passam periodicamente por reciclagem. $\mathrm{O}$ acompanhamento constante do comportamento dos animais pelos profissionais, com correção imediata de desvios ou mudança de manejo em algumas ocasiões, é fundamental.

Nos períodos de férias escolares, quando as cadelas não participam das atividades de TAA, os animais apresentaram maior irritabilidade e agitação, o que foi controlado com a intensificação de passeios e atividades físicas.

A escolha da raça labrador retriever foi fundamentada em sua adaptabilidade e entusiasmo para trabalhar com pessoas. São cães que podem auxiliar desde a busca de sobreviventes soterrados sob escombros após terremotos até a procura de drogas e explosivos. É uma raça muito comum para TAA, pois é de adestramento simples, tem comportamento alegre, carinhoso e leal, gosta de aprender e é extremamente receptiva (ALDERTON, 2014).

Ao longo dos 12 anos de atuação do projeto Cão-Cidadão-Unesp, a maioria dos animais selecionados foi da raça labrador ou golden retriever. Nas tentativas de utilização de outras raças, como border collie e lhasa apso, o rendimento desejado não foi obtido. Comprovou-se, portanto, a maior aptidão dos retrievers para essa atividade, como reportado por Alderton (2014), em especial, dos labradores, que, em comparação aos golden retrievers, possuem pelagem mais curta, o que facilita o manejo (Figura 3).

Durante o período de observação do presente estudo, não foram identificados distúrbios de comportamento que influenciassem o rendimento dos animais nas terapias, que estavam sempre alegres, dispostos ao trabalho $\mathrm{e}$ às brincadeiras, receptivos aos afagos e interagiam com interesse com os idosos.

As vacinas foram aplicadas rigorosamente dentro do esquema profilático preconizado e as cadelas não contraíram doenças graves. Um dos animais apresentou quadro de otite infecciosa que foi tratado com medicação tópica e evoluiu para a cura em poucos dias. Uma das cadelas apresentou diarreia transitória, atribuída ao oferecimento de ração em quantidade maior do que a habitual em um final de semana, o que foi imediatamente corrigido.

Houve a ocorrência de significativa infestação por carrapatos, que foi atribuída ao contato dos animais com locais de grande infestação (estábulos e pastos) 
e à possível resistência aos princípios ativos até então utilizados como carrapaticidas (fipronil e ivermectina). Por outro lado, a necessidade de banhos frequentes para a participação dos cães nas terapias pode contribuir para a baixa eficácia de medicamentos de uso tópico como o fipronil. Desta maneira, foi introduzido novo tratamento com fluralaner (Bravecto ${ }^{\oplus}$ ) por via oral a cada quatro meses, que, até o momento, tem demonstrado eficácia e não foi mais observada a infestação por ectoparasitas.

Almeida, Silva e Medeiros (2014), em um estudo sobre ocorrência de helmintos e protozoários intestinais em seres humanos idosos, verificaram que a Giárdia lamblia era uma das parasitoses mais comuns $(13,04 \%)$. A Giardia lamblia (Giardia intestinalis ou Giardia duodenale) é um protozoário que parasita intestinos de seres humanos, causando giardíase, zoonose que se manifesta com sintomas de diarreia e cólica. Cães terapeutas que frequentam asilos e hospitais devem estar sempre protegidos contra a Giardia sp, dado que nesses ambientes os pacientes possuem imunidade comprometida. Apesar de os animais descritos neste trabalho não estarem sendo vacinados contra Giardia sp, os exames coprológicos periodicamente efetuados não revelaram a presença do protozoário.

Outra parasitose preocupante é a erliquiose, também conhecida como doença do carrapato, causada por bactérias gram-negativas, intracelulares, pertencentes à ordem Rickettsiales, gêneros Ehrlichia e Anaplasma, que podem parasitar leucócitos, eritrócitos e plaquetas, levando a alterações em vários órgãos. A incidência de casos de erliquiose vem aumentando nos últimos anos, tanto nos animais como no homem (DAGNONE; MORAIS; VIDOTTO, 2001).

Erliquiose e anaplasmose são transmitidas por carrapatos e é função do médico-veterinário garantir o controle adequado de ectoparasitas nos animais terapeutas e, em casos de doença, realizar o tratamento adequado, pois cães acometidos por esses parasitas são incapacitados de realizar adequadamente seus trabalhos, uma vez que as doenças causam apatia, depressão, anorexia, hemorragias e comprometem o sistema imunológico dos animais (MONTEIRO, 2007).

Em uma das cadelas do projeto foi firmado o diagnóstico laboratorial de erliquiose, com ausência de sintomatologia clínica, achado de um esfregaço sanguíneo realizado para sua seleção para doação de sangue. $\mathrm{O}$ animal foi submetido ao tratamento completo com Vibramicina ${ }^{\oplus}$, (cujo princípio ativo é a doxiciclina) na dose de $5 \mathrm{mg} / \mathrm{kg}$, durante 28 dias, sem maiores intercorrências. Durante todo o tratamento, a cadela foi afastada da atividade de TAA, e a doença foi atribuída à infestação por carrapatos descrita anteriormente.

O manejo diário de alimentação, a oferta de água fresca, o acesso a maior espaço e à exposição ao sol durante dia e o recolhimento a local telado ao final do dia foram garantidos e fiscalizados pelos estudantes e médicos-veterinários envolvidos.

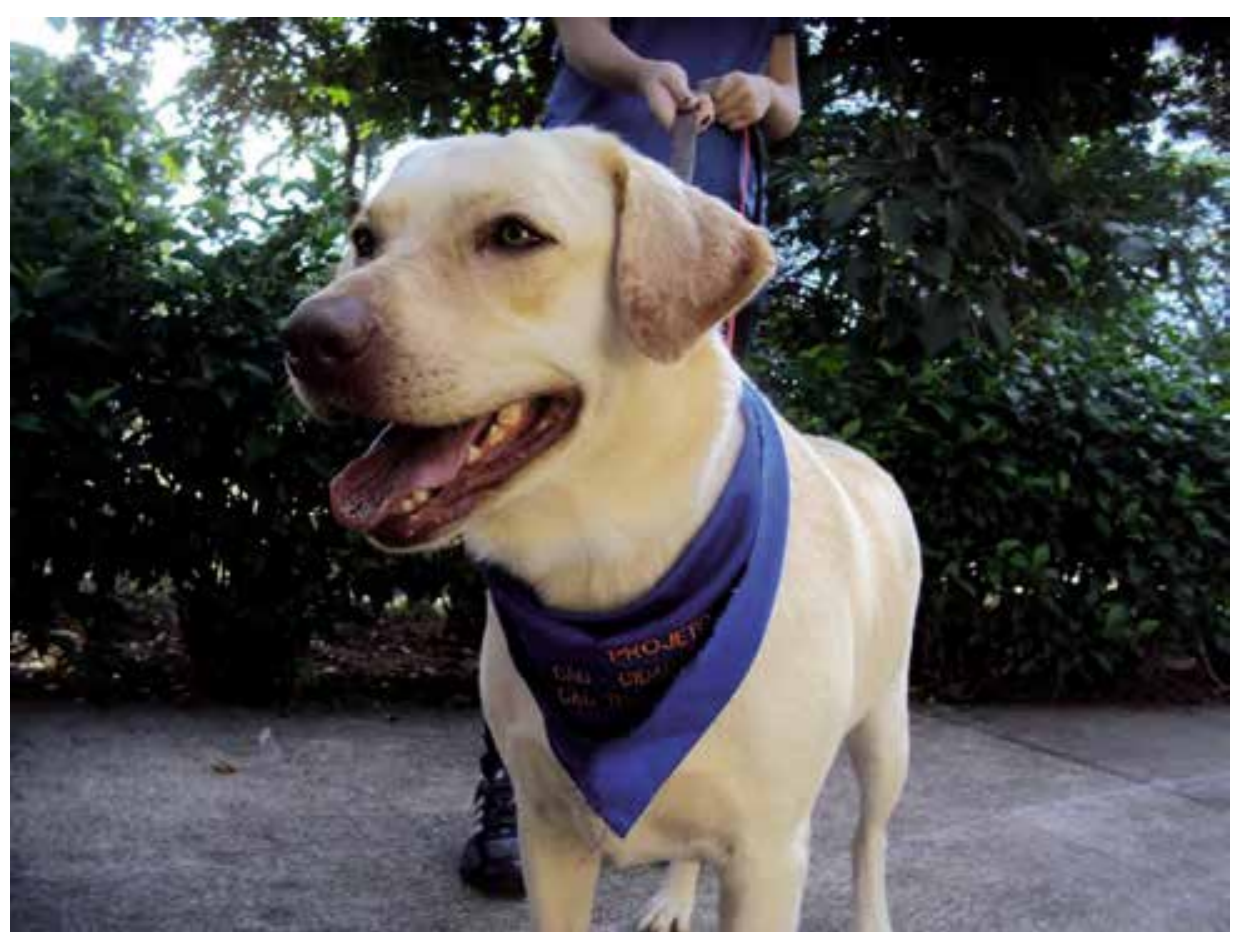

Figura 3 - Clara, um dos animais que participou do projeto como terapeuta. Fonte: Silva (2015). 
Após um ano e meio de trabalho, pode-se observar inúmeros benefícios alcançados pela TAA. O contato dos idosos com os animais alivia sensações de solidão e depressão dos pacientes. Sensações de atenção, amor e respeito também são estimuladas e culminam em acentuado aumento da autoestima.

A constância das visitas também é de extrema importância. A regularidade com que são realizadas atividades resulta em benefícios à memória dos idosos. Sendo assim, deve-se evitar que visitas sejam interrompidas por muito tempo, pois os pacientes criam expectativas e frustrá-los não seria ideal para o tratamento. Durante a interrupção de visitas por algum motivo, a ausência foi amplamente notada pelos idosos.

Observou-se que não apenas os pacientes alcançaram resultados positivos, mas também os participantes do projeto. Os alunos da instituição de ensino que participam do projeto (seja como bolsistas, voluntários ou estagiários) puderam ter noções básicas da função de um médico-veterinário nessa atividade, de acordo com o projeto político-pedagógico do próprio curso, que prevê a formação de profissionais comprometidos com a melhoria da sociedade que os cerca. Além de frequentar as visitas, os alunos acompanharam a rotina dos animais terapeutas. Estiveram presentes em momentos que vão desde a realização de exames e procedimentos clínicos até passeios e banhos. Essas ações são fundamentais para a formação do aluno, pois, dessa maneira, abrem conhecimento sobre um novo mercado de trabalho em grande ascensão, e reforçam a responsabilidade do médico-veterinário nas várias áreas de atuação.

\section{Conclusões}

De acordo com a pesquisa realizada e os métodos aqui expostos, pode-se confirmar a importância do papel do médico-veterinário nas atividades de TAA, permitindo que os animais estejam sempre aptos a realizar seu trabalho com excelência, contribuindo para o avanço positivo na saúde dos pacientes em tratamento e para melhor qualidade de vida.

A participação do médico-veterinário é fundamental para proteger e, eventualmente, prevenir que o animal sofra qualquer dano em relação à saúde física e comportamental.
A participação de estudantes de graduação em projetos de extensão como este tem sido uma importante maneira de conferir comprometimento social, desenvolvimento da cidadania e responsabilidade à sua formação profissional.

\section{Referências}

ABREU, C. C. et al. Atividade assistida por animais no Lar Augusto Silva. In: CONGRESSO DE EXTENSÃO DA UFLA, 4., 2009, Lavras. Trabalhos... Lavras: UFLA, 2009.

ALDERTON, D. Cães: como escolher o companheiro ideal para você. São Paulo: Quarto, 2014. 176 p.

ALMEIDA, F. S.; SILVA, R. C.; MEDEIROS, J. S. Ocorrência de helmintos e protozoários intestinais em idosos. Revista de Biologia e Farmácia e Manejo Agrícola, Paraíba, v. 10, n. 4, p. 78-82, 2014.

ANDERLINE, G. P. O. S.; ANDERLINE, G. A. Benefícios do envolvimento do animal de companhia (cão e gato), na terapia, socialização e bem-estar de pessoas e o papel do médicoveterinário. Revista CFMV, Brasília, DF, n. 41, p. 70-75, 2007.

DAGNONE, A. S.; MORAIS, H. S. A.; VIDOTTO, O. Erliquiose nos animais e no homem. Semina: Ciências Agrárias, Londrina, v. 22, n. 2, p. 191-201, 2001.

DOTTI, J. Terapia \& animais. São Paulo: Noética, 2005. 294 p.

FLÔRES, L. N. Os benefícios da interação homem-animal e o papel do médico-veterinário. 2009. 34 p. Trabalho de conclusão de curso (Especialização em Clínica Médica de Pequenos Animais) - Universidade Federal Rural do Semi-Árido, Porto Alegre, 2009.

MONTEIRO, S. G. Caderno didático de aula prática de parasitologia veterinária. 2. ed. Santa Maria: Universidade Federal de Santa Maria, 2007. 230 p.

PEREIRA, M. J. F.; PEREIRA, L.; FERREIRA, M. L. Os benefícios da terapia assistida por animais: uma revisão bibliográfica. Saúde coletiva, São Paulo, v. 4, n. 14, p. 62-66, 2007.

POR QUE os bichos tornam as nossas vidas mais saudáveis? Revista Cláudia, São Paulo, n. 12, p. 23-25, 2001. Entrevista concedida por Dennis Turner à redação da Revista Claúdia.

VOLPI, D.; ZADROZNY, V. G. P. Benefícios da TAA: uma contribuição da psicologia. 2012. 33 f. Trabalho de conclusão de curso (Graduação em Psicologia) - Centro de Ciências da Saúde, Universidade Regional de Blumenau, Blumenau, 2012. 